\title{
Estradiol Differentially Regulates c-Fos after Focal Cerebral Ischemia
}

\author{
Shane W. Rau, ${ }^{1}$ Dena B. Dubal, ${ }^{1,2}$ Martina Böttner, ${ }^{3}$ and Phyllis M. Wise ${ }^{3}$ \\ ${ }^{1}$ Department of Physiology, University of Kentucky College of Medicine, Lexington, Kentucky 40536, ${ }^{2}$ Department of Neurology, University of California at \\ San Francisco, San Francisco, California 94143, and ${ }^{3}$ Department of Neurobiology, Physiology, and Behavior, Division of Biological Sciences, University of \\ California Davis, Davis, California 95616
}

\begin{abstract}
Estrogen replacement therapy enhances mood, delays cognitive decline, and reduces the risk of neurodegeneration. Our laboratory has shown previously that pretreatment with low physiological levels of estradiol protects against middle cerebral artery occlusion (MCA0)induced brain injury during late phases of neuronal cell death. Immediate early genes (IEGs) are induced by various forms of brain injury, and their induction is known to be a critical step in programmed cell death. The current study tested the hypothesis that the ability of estradiol to reduce MCAO-induced cell death involves attenuation of expression of one or more IEGs. We examined the effects of MCAO on the temporospatial pattern of IEG expression and the modulation of this pattern by estradiol replacement. Rats were ovariectomized and treated with either vehicle or low physiological concentrations of estradiol. One week later, rats underwent MCAO and brains were collected 1, 4, 8, 16, and $24 \mathrm{hr}$ later. We assessed IEG mRNAs in discrete regions of brain by RT-PCR at $24 \mathrm{hr}$. We examined expression of c-Fos mRNA and protein in greater detail using in situ hybridization and immunohistochemistry to delineate the time course and specific regions of cortex in which estradiol influenced its expression. Our results reveal that $c$-fos, fos $B, c$-jun, and jun $B$ levels were upregulated at $24 \mathrm{hr}$. Furthermore, estradiol selectively affected the expression of c-Fos mRNA and protein by attenuating the injury-induced increase in a time- and region-specific manner. Our findings strongly suggest that the ability of estradiol to protect against MCA0-induced cell death involves attenuation of c-Fos induction.
\end{abstract}

Key words: estradiol; immediate early gene; middle cerebral artery occlusion; stroke; apoptosis; cell death

\section{Introduction}

Stroke is the third leading cause of death in the United States (American Heart Association, 2001). The age-related increase in stroke risk is compounded in women. In the 45-54 year age group, stroke prevalence in women is half that in men; however, in the 65-74 year group, women and men exhibit almost equal stroke prevalence (American Heart Association, 2001). In the last century, the average life expectancy has increased from 47 to 77 years (Futterman and Lemberg, 2000), but the average age of the menopause has remained fixed at 51 years (Brambilla and McKinlay, 1989; Luoto et al., 1994; Bromberger et al., 1997). Therefore, a larger proportion of women are living an increasing number of years in a postmenopausal, hypoestrogenic state.

Estrogens have been established as potent neuroprotective and neurotrophic factors (Calakos and Scheller, 1994; ToranAllerand et al., 1999; Green and Simpkins, 2000; Hurn and Macrae, 2000; Brinton, 2001; Garcia Segura et al., 2001; Wise et al., 2001). Clinical studies have demonstrated that estrogens enhance mood and cognition and delay cognitive decline (Paganini-Hill et al., 1988; Kawas et al., 1997; Sherwin, 1999); however, several

Received April 29, 2003; revised Sept. 9, 2003; accepted Sept. 12, 2003.

This work was supported by National Institutes of Health Grants AG17164, AG02224, and AG00242 (P.M.W.)

Correspondence should be addressed to Dr. Phyllis M. Wise, Division of Biological Sciences, University of California, Davis, One Shields Avenue, Davis, CA 95616-8536. E-mail: pmwise@ucdavis.edu.

Copyright $\odot 2003$ Society for Neuroscience $\quad 0270-6474 / 03 / 2310487-08 \$ 15.00 / 0$ recent studies have failed to demonstrate an amelioration of cognitive dysfunction in women already suffering from Alzheimer's disease (Marder and Sano, 2000; Roof and Hall, 2000; Wang et al., 2000). The Women's Health Initiative reported an increased risk for stroke, among other conditions (Writing Group for the Women's Health Initiative Investigators, 2002). Although the clinical literature gives conflicting results, various in vivo and in vitro basic science studies provide striking evidence for cellular and molecular mechanisms underlying clear neuroprotective and neurotrophic actions of estradiol. Estrogens attenuate neuronal injury associated with cerebral ischemia and brain trauma in young and aging male and female rodents (Hall et al., 1991; Behl et al., 1997; Alkayed et al., 1998, 2000; Dubal et al., 1998; Miller et al., 1998; Toung et al., 1998; Rusa et al., 1999; Sawada and Shimohama, 2000; Dubal and Wise, 2001; Kim et al., 2001; Mendelowitsch et al., 2001; Jover et al., 2002).

Our laboratory has shown that pretreatment with low physiological levels of estradiol protects against permanent middle cerebral artery occlusion (MCAO) (Dubal et al., 1998). Protection is specific to the late phase of injury and to the cortex, which is known to exhibit programmed cell death (PCD) (Chopp and Li, 1996; Li et al., 1998; Namura et al., 1998; Guegan and Sola, 2000; Sharp et al., 2000). The protective effects of estradiol have been associated with alterations in the expression of multiple genes (Dubal et al., 1999). Immediate early genes (IEGs) are elevated in ischemic injury (Kinouchi et al., 1994a) and have been 
shown to be involved in PCD cascades (Estus et al., 1994; Ferrer et al., 2000; Sharp et al., 2000).

The purpose of this study was to test the hypothesis that estradiol may attenuate ischemic injury, in part, by blocking increases in IEG expression in ischemic penumbra. We examined the effects of estradiol pretreatment and MCAO on IEG expression in the cerebral cortex of ovariectomized female rats that were treated with estradiol or vehicle. Our results show that estradiol selectively attenuates the injury-mediated increase in c-Fos expression.

\section{Materials and Methods \\ Cerebral ischemia}

Female Sprague Dawley rats (225-275 gm) were maintained in a 14/10 hr light/dark cycle with ad libitum access to food and water. Rats were bilaterally ovariectomized under methoxyflurane anesthesia to eliminate endogenous estradiol production and then implanted with a SILASTIC capsule containing oil or $17 \beta$-estradiol $(180 \mu \mathrm{g} / \mathrm{ml})$. This paradigm of low-dose estradiol treatment produces $\sim 20 \mathrm{pg} / \mathrm{ml}$ in rats (Dubal and Wise, 2001). These levels are equivalent to basal circulating levels found in the estrous cycle of rats (Smith et al., 1975). After $7 \mathrm{~d}$, rats underwent MCAO or sham surgery. Rats were anesthetized with ketamine/ acepromazine (80.0/0.52 mg/kg, i.p.). Body temperature was monitored with a rectal probe and maintained within $1{ }^{\circ} \mathrm{C}$ of normothermia (36$38^{\circ} \mathrm{C}$ ). The right middle cerebral artery was permanently occluded using previously described methods (Dubal et al., 1998). Briefly, a 4/0 monofilament suture was inserted through the internal carotid artery to the base of the middle cerebral artery. Sham surgical animals underwent the entire procedure except that the artery was not occluded.

Two separate groups of animals were collected by the above methods. These groups and the experiments performed with them will be referred to as experiments 1 and 2. Animals from experiment 1 were used for initial RT-PCR studies as well as for the in situ hybridization and immunohistochemistry studies. For experiment 1 , brains were collected at 1,4 , 8,16 , or $24 \mathrm{hr}$ after the onset of ischemia $(n=6-10$ per experimental group). Animals from experiment 2 were used for the final set of RT-PCR studies. Only $24 \mathrm{hr}$ brains were collected for experiment $2(n=6$ per experimental group), and no sham animals were collected.

\section{Reverse transcriptase-PCR studies \\ Microdissection}

In the case of experiment 1 , brains were fresh frozen on dry ice and stored at $-80^{\circ} \mathrm{C}$ until coronal sections of these brains could be cut on a cryostat. In animals from the $24 \mathrm{hr}$ group, three $200 \mu \mathrm{m}$ sections were taken from the "test zone" (bregma +1.2 to bregma -0.8 ) (Paxinos and Watson, 1997) and stored on slides at $-80^{\circ} \mathrm{C}$ until microdissection could be performed. The same anatomic area (i2, c2; see Fig. 1) was microdissected from each of the $200 \mu \mathrm{m}$ sections for a given brain and combined as a single sample (e.g., one i2 sample and one c2 sample for each animal). For experiment 2, alternating $1 \mathrm{~mm}$ fresh sections of brain were collected using a brain matrix (Activational Systems) and then stained in 2\% triphenyl-tetrazolium chloride (TTC) to visualize injury or frozen on dry ice and stored at $-80^{\circ} \mathrm{C}$ for inclusion in RT-PCR studies. The area of the cortex analyzed for gene expression was selected using the following criteria. We first examined tissue from a $1 \mathrm{~mm}$ TTC-stained coronal section corresponding to the test zone. The adjacent frozen $1 \mathrm{~mm}$ section was then microdissected for use in gene expression studies. For all samples, anatomically similar regions were dissected, with care being taken to avoid collecting infarcted tissue from any sample (see Fig. 1). For experiment 1 , only areas i2 and c2 were used. For experiment 2, all areas (i1, i2, $\mathrm{c1}$, and c2) were microdissected and used.

\section{cDNA preparation}

Total RNA was isolated from microdissected samples by the method of Chomczynski and Sacchi (1987). Total RNA $(0.5 \mu \mathrm{g})$ from each sample was reverse transcribed to produce cDNA using a protocol described previously (Dubal et al., 1999). The same procedure was performed on samples using a reaction solution without reverse transcriptase (RT) to check for genomic contamination.

\section{PCR amplification}

We used RT-PCR methods to determine relative changes in gene expression at the mRNA level as described previously (Dubal et al., 1999). Briefly, for each gene examined, we generated standard curves of cycle number to determine the optimum cycle number within the linear range for PCR amplification. This was determined to be between 21 and 28 cycles for all genes examined.

Experiment 1. For each gene, stock solutions were prepared containing $1.5 \mathrm{~mm} \mathrm{MgCl} 2,1 \times$ reaction buffer, $10 \mu \mathrm{Ci}$ of $\left[{ }^{32} \mathrm{P}\right] \mathrm{dCTP}(3000 \mathrm{Ci} /$ mmol) (NEN, Boston, MA), $0.5 \mathrm{~mm}$ dNTP mix, $1 \mu \mathrm{M}$ each primer, and $1.5 \mathrm{U}$ of Taq polymerase (Invitrogen). The stock solution was aliquoted ( $49 \mu$ l per tube), and $1 / 30$ of cDNA (from reverse transcription reaction) was added to each sample tube. Samples were then thermocycled for PCR amplification (Touchdown thermocycler; Hybaid, Middlesex, UK) according to reaction conditions optimized for each separate gene. PCR products were then resolved by PAGE. The gels were dried, and products were visualized using a PhosphorImager (Molecular Dynamics, Sunnyvale, CA).

Experiment 2. The RT-PCR procedures were all identical to experiment 1 with the following exceptions. (1) No radioactive dCTP, (2) $\sim 0.1$ mu dNTP mix, (3) stock solution was aliquoted as $14 \mu \mathrm{l}$ per tube, and (4) after products were resolved by PAGE, gels were stained in a solution of SYBR gold nucleic acid gel stain (Molecular Probes, Eugene, OR), and products were visualized using a PhosphorImager.

All of the oligonucleotide sequence pairs used for gene amplification generated PCR products of expected sizes. Primers used for both experiments are as follows: L-27A sense primer, $5^{\prime}$-ATCGGTAAGCACCG-

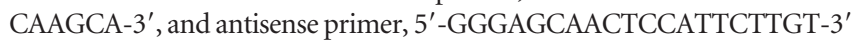
(214 bp) (Hoshimaru et al., 1996); c-fos sense primer, 5'-AATAAGATGGCTGCAGCCAA-3', and antisense primer, 5'-TTGGCAATCTCGGTCTGCAA-3' (116 bp) (Estus et al., 1997); fosB sense primer, 5'-GAGATCGCCGAGCTGCAAAA-3', and antisense primer 5' -TTGTGGGCCACCAGGACAAA-3' (58 bp) (Estus et al., 1997); junB sense primer, 5'-GGGAATTCAAACCCACCTTGGCGCTCAA- ${ }^{\prime}$, and antisense primer 5'-GCGGATCCGGACCCTTGAGACCCCGATA-3' (69 bp) (Estus et al., 1997); c-jun sense primer, 5'-ACTCAGTTCTTGTGCCCCAA-3', and antisense primer 5' -CGCACGAAGCCTTCGGCGAA-3' (64 bp) (Estus et al., 1997); junD sense primer, 5'-GGGAATTCAAGGCTGATCATCCAGTCCAA-3', and antisense primer 5' -GGGGATCCGCCACCTTCGGGTAGAGGAA-3' (128 bp) (Estus et al., 1997).

\section{In situ hybridization}

\section{Tissue preparation}

In addition to the $200 \mu \mathrm{m}$ sections taken from the test zone in experiment 1 animals, $18 \mu \mathrm{m}$ coronal sections were also taken for use in both the in situ hybridization and immunohistochemical studies that follow. The sections were mounted on slides and stored at $-80^{\circ} \mathrm{C}$ until they were processed for in situ hybridization or immunohistochemistry.

\section{Probe preparation}

The $c$-fos probe was generated using a template plasmid containing a 1352 bp EcoRI-XhoI fragment described previously (Curran et al., 1987) (generously provided by Dr. Robert Steiner, University of Washington School of Medicine, Seattle, WA). A riboprobe was transcribed in the presence of $13.3 \mu \mathrm{M} \alpha$-thio ${ }^{35}$ S-labeled UTP.

\section{Hybridization}

Coronal sections $(18 \mu \mathrm{m})$ from each animal (two sections per slide, one slide per animal) were processed simultaneously in a single-label in situ hybridization assay according to the method of Wise et al. (1992), with modifications. Briefly, sections were fixed in phosphate-buffered $4 \%$ paraformaldehyde, treated with $0.25 \%$ acetic anhydride in $0.1 \mathrm{M}$ triethanolamine, $\mathrm{pH}$ 8.0, and dehydrated. Hybridization buffer (50 $\mu$ l) containing $600 \mathrm{ng} / \mathrm{ml}$ labeled $c$-fos cRNA was applied to each slide. Slides were coverslipped and incubated in humid chambers at $45^{\circ} \mathrm{C}$ for $18 \mathrm{hr}$. Sections were treated with RNase A $(25 \mu \mathrm{g} / \mathrm{ml})$, washed under conditions of increasing stringency, including a $1 \mathrm{hr}$ wash at $60^{\circ} \mathrm{C}$ in $0.2 \times$ SSC, dehy- 
drated in ethanol containing $300 \mathrm{~mm}$ ammonium acetate, and air dried. Slides were then apposed to film for $29 \mathrm{hr}$.

Slides from the test zone were used in this experiment. Three spatially juxtaposed circular areas of frontal and parietal cortices from one section per animal were analyzed on the films using pixel count and area arrays via BIOQUANT software (see Fig. 5). Densitometric values from the three regions were combined to yield a single value per animal. The three regions extended from the central sulcus laterally to the region of a typical infarct border from a $24 \mathrm{hr}$ oil-treated animal. This allowed for identical areas of analysis in oil- and estradiol-treated rats across time points without the risk of analyzing dead, infarcted tissue.

\section{Immunocytochemistry}

The entire immunohistochemical procedure was performed on slidemounted sections, with one slide (two sections per slide) being used per animal. Sections were fixed in phosphate-buffered $4 \%$ paraformaldehyde. On day 1 , sections were washed with $0.05 \mathrm{~m}$ Tris, $\mathrm{pH}$ 7.4. This was followed by a $1 \mathrm{hr}$ blocking step at room temperature (Tris, $1 \%$ Triton $\mathrm{X}-100,10 \%$ heat inactivated horse serum) and then incubation in blocking buffer containing a polyclonal antibody directed against a peptide mapping to the amino terminus of c-Fos p62 of human origin [1:5000; Santa Cruz Biotechnology, Santa Cruz, CA; c-Fos(4), sc-52] overnight at $4^{\circ} \mathrm{C}$. Sections were washed again in Tris and then incubated for $1 \mathrm{hr}$ in blocking buffer containing biotin-conjugated secondary anti-rabbit anti-IgG (1:1000; Jackson ImmunoResearch, West Grove, PA). After another wash step the sections were incubated for $1 \mathrm{hr}$ in avidin-biotin complex (ABC) solution for $1 \mathrm{hr}$ (Vectastain Kit, Vector Laboratories, Burlingame, CA). Antibody complexes were visualized with nickelenhanced DAB (3,3'-diaminobenzidine). In control experiments, immunohistochemical reactions lacking either c-Fos primary antibody or the secondary antibody were performed and showed no immunoreactive cells. Additionally, immunohistochemical reactions using c-Fos primary antibody preabsorbed with 10 -fold excess c-Fos blocking peptide (Santa Cruz Biotechnology; sc-52P) showed no immunoreactivity demonstrating the specificity of the antibody. c-Fos immunoreactive cells were counted within ipsilateral and contralateral frontoparietal cortex from one section per animal using an object counts array via BIOQUANT software in seven separate $20 \times$ scope fields. The frontal and parietal cortical areas of tissue were chosen for cell counts because they represent peri-infarct cortex after MCAO in our paradigm. In the frontal cortex, two fields were counted that bordered on the central sulcus. One of these fields also encompassed the outer rim of cortical tissue and the other included the outer rim of the corpus callosum. A third field encompassing the central layers of cortex was counted in one $20 \times$ field lateral to the first two fields. In the parietal cortex, a field encompassing central layers of cortex lateral to the third frontal cortex field was counted. In one $20 \times$ field lateral to this first parietal field, two fields were counted, one encompassing the outer rim of cortex and the other including the border of the corpus callosum. The fourth parietal field encompassed the central layers of cortex, in one $20 \times$ field lateral to the previous two fields. Using this pattern of movement from field to field in each section, equal sampling was ensured from animal to animal. The counts from all seven fields were combined to obtain a single cell number for each coronal section.

\section{Data analysis}

Data were analyzed by two- or three-way ANOVA, depending on the experiment. For time course experiments (in situ hybridization and immunohistochemistry), data were separated into an early-phase injury $(1-8 \mathrm{hr})$ and a late-phase injury (16-24 hr). Significant interactions were probed using Newman-Keuls tests. All data are expressed as mean \pm SEM. Differences were considered statistically significant when $p<0.05$.

\section{Results}

\section{Estradiol specifically modulates injury-induced $c$-fos} mRNA levels

Figure 1 shows representative TTC-stained brain sections from an ovariectomized oil- and estradiol-treated rat killed at $24 \mathrm{hr}$

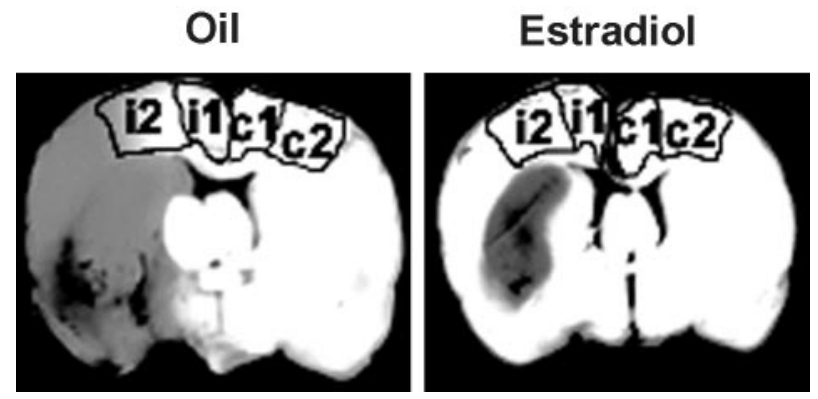

Figure 1. Representative images of sections from oil- and estradiol-treated rats at $24 \mathrm{hr}$ after initiation of permanent middle cerebral artery occlusion. Infarcted tissue is dark, whereas live tissue is light. An adjacent $1 \mathrm{~mm}$ frozen coronal section was microdissected in anatomically equivalent areas on the ipsilateral (i1, i2) and contralateral ( $\left.\mathrm{c}_{1}, \mathrm{c} 2\right)$ cortex from oil- and estradiol-treated animals as outlined.

after MCAO. The outlined regions correspond to tissue that was microdissected from adjacent sections for RNA analysis by semiquantitative RT-PCR. Tissue of animals from two separate experiments was used in RT-PCR studies. In experiment 1, mRNA levels within the i2 and $\mathrm{c} 2$ regions were quantified, whereas in experiment 2, mRNA levels were measured in i1, i2, c1, and c2 regions.

Baseline gene expression among the experimental groups was determined relative to the marker, ribosomal L-27A. L-27A gene expression did not change with injury or estradiol treatment in experiment 1 (Table 1) or experiment 2 (data not shown), indicating that the amount of live tissue was represented equally among treatment groups (ischemic and sham, oil and estradioltreated animals). Values for the immediate early genes from experiment 1 (Table 1) show that estradiol or ischemia, or both, selectively alter gene expression after the induction of injury. None of the genes examined showed any estradiol-induced alterations in sham animals.

\section{Experiment 1}

Table 1 lists data for all IEGs examined in experiment 1. ANOVA analysis shows a significant effect of hemisphere for all IEGs $\left({ }^{*} p<0.05\right)$ with the exception of $j u n D$. Levels of mRNA of $c$-fos, fos $B, j u n B$, and $c$-jun increased significantly on the ipsilateral side compared with the contralateral side of injured animals. Estradiol significantly attenuated the injury-mediated increase in $c$-fos mRNA at $24 \mathrm{hr}$. ANOVA analysis of $c$-fos mRNA in injured animals showed a significant effect of hemisphere $\left({ }^{*} p<0.05\right)$ and a significant effect of treatment $(p<0.05)$ with no interaction. Similar trends were observed in fosB and junB mRNA levels, but they did not reach statistical significance (Table 1). Because these trends were intriguing, we performed experiment 2, adding another microdissected area in each hemisphere (i1, c1).

\section{Experiment 2}

Figure 2 comprises a composite of PCR results illustrating representative expression of L-27A and IEGs from experiment 2. Figures 3 and 4 show $c$-fos, fos $B$, and jun $B$ levels on the ipsilateral and contralateral sides in oil- and estradiol-treated rats that have undergone MCAO. MCAO results in an upregulation of $c$ - fos, fos $B$, and junB mRNA levels as illustrated by significant increases in ipsilateral compared with contralateral cortical regions $(p<$ $0.05)$. Estradiol specifically attenuated $c$-fos mRNA expression in the il and cl cortical regions at $24 \mathrm{hr}$ after the onset of ischemia $\left({ }^{*} p<0.05\right)$ (Fig. 3). In contrast, estradiol replacement did not affect injury-induced or baseline fosB or junB expression (Fig. 4). 
Table 1. Experiment 1: gene expression of cellular marker L-27A and IEG family members

\begin{tabular}{|c|c|c|c|c|c|c|c|c|}
\hline & \multicolumn{4}{|l|}{ MCAO } & \multicolumn{4}{|l|}{ Sham } \\
\hline & \multicolumn{2}{|l|}{ Ipsi } & \multicolumn{2}{|l|}{ Contra } & \multicolumn{2}{|l|}{ Ipsi } & \multicolumn{2}{|l|}{ Contra } \\
\hline & Oil & Estradiol & 0il & Estradiol & Oil & Estradiol & Oil & Estradiol \\
\hline$L-27 \mathrm{~A}$ & $1.28 \pm 0.13$ & $1.31 \pm 0.10$ & $1.29 \pm 0.03$ & $1.36 \pm 0.05$ & $1.39 \pm 0.07$ & $1.36 \pm 0.05$ & $1.31 \pm 0.05$ & $1.39 \pm 0.10$ \\
\hline$c-f o s$ & $2.46 \pm 0.22^{*}$ & $1.85 \pm 0.28^{* *}$ & $1.16 \pm 0.18$ & $0.98 \pm 0.14^{* *}$ & $0.76 \pm 0.23$ & $0.52 \pm 0.08$ & $0.55 \pm 0.08$ & $0.55 \pm 0.07$ \\
\hline fos $B$ & $2.60 \pm 0.25^{*}$ & $1.89 \pm 0.33^{*}$ & $0.91 \pm 0.11$ & $0.70 \pm 0.06$ & $0.58 \pm 0.09$ & $0.55 \pm 0.07$ & $0.68 \pm 0.10$ & $0.62 \pm 0.06$ \\
\hline junB & $1.50 \pm 0.14^{*}$ & $1.19 \pm 0.12^{*}$ & $0.96 \pm 0.10$ & $0.94 \pm 0.09$ & $0.75 \pm 0.12$ & $0.66 \pm 0.06$ & $0.76 \pm 0.07$ & $0.74 \pm 0.11$ \\
\hline c-jun & $1.53 \pm 0.20^{*}$ & $1.51 \pm 0.17^{*}$ & $0.98 \pm 0.06$ & $1.04 \pm 0.06$ & $0.83 \pm 0.08$ & $0.73 \pm 0.08$ & $0.89 \pm 0.12$ & $0.83 \pm 0.10$ \\
\hline junD & $1.19 \pm 0.17$ & $1.08 \pm 0.05$ & $1.23 \pm 0.10$ & $1.04 \pm 0.08$ & $1.10 \pm 0.08$ & $1.05 \pm 0.09$ & $1.04 \pm 0.06$ & $0.87 \pm 0.22$ \\
\hline
\end{tabular}

Tissue samples were taken from oil- and estradiol-treated MCAO and sham animals at $24 \mathrm{hr}$ after surgery. Ipsi and Contra refer to areas i2 and c2, respectively (Fig. 1). Baseline levels of L-27A were not affected by ischemia or by estradio treatment, indicating that the overall amount of live tissue is equally represented among experimental groups. Gene expression of IEG family members in sham and injured rat cortex were normalized to $\mathrm{L}-27 \mathrm{~A}$ values. The expression of specific genes increased in ipsilateral ischemic cortex $\left({ }^{*} p<0.05\right)$. Estradiol attenuated the injury-mediated increase in $c$-fos mRNA levels $\left({ }^{* *} p<0.05\right)$. ANOVA demonstrates effect of treatment and of hemisphere with no interaction. Estradiol did not alter expression of any genes in sham animals.

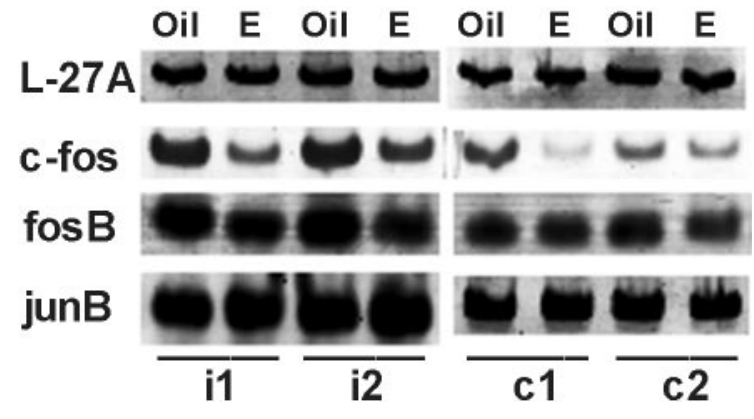

Figure 2. Composite of $P C R$ results showing representative expression of a control gene $(\mathrm{L}-27 \mathrm{~A})$ and IEG family members ( $c$-fos, fos $B$, junB $)$ in tissue samples from the ipsilateral (i1, i2) and contralateral ( $\mathrm{C} 1, \mathrm{C2})$ cortex of oil-treated and estradiol-treated (labeled E) rats $24 \mathrm{hr}$ after the initiation of MCAO from experiment 2. Regions $\mathrm{i} 1, \mathrm{i} 2, \mathrm{C} 1$, and $\mathrm{c} 2$ are as defined in Figure 1.

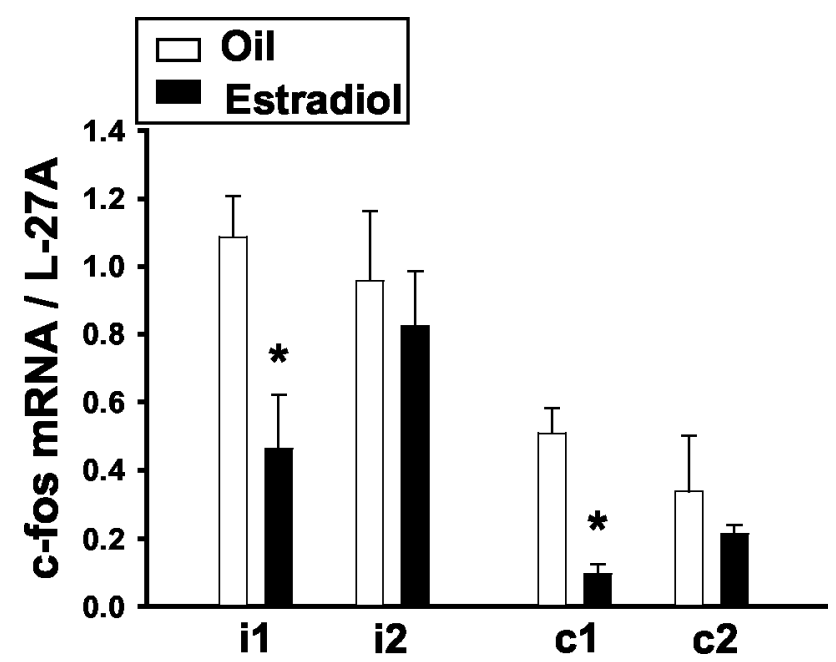

Figure 3. Estradiol significantly attenuates the injury-mediated increase in c-fos mRNA levels in area i1 $\left({ }^{*} p<0.05\right)$. Estradiol also reduces $c$-fos mRNA levels in area $c 1\left({ }^{*} p<0.05\right)$. In the absence of estradiol, $c-$-fos $m$ RNA is increased in areas 11 and $\mathrm{i} 2$ in comparison with areas $c 1$ and C2, respectively $(p<0.05)$. Estradiol had no effect on levels of $c-$ fos mRNA in areas i2 or $c 2$. Tissue samples were taken from animals in experiment 2 at $24 \mathrm{hr}$ after the initiation of MCAO. Data are represented as mean \pm SEM.

Estradiol attenuates injury-induced $c$-fos mRNA in cortex during the late phase of ischemic injury

To further explore the estradiol-induced modulation of the temporospatial pattern of $c$-fos gene expression after injury, in situ hybridization was performed on coronal sections of the same animals with a radiolabeled probe to $c$-fos. In all three areas (Fig. $5)$ of ischemic cortex that were examined in oil- and estradiol-
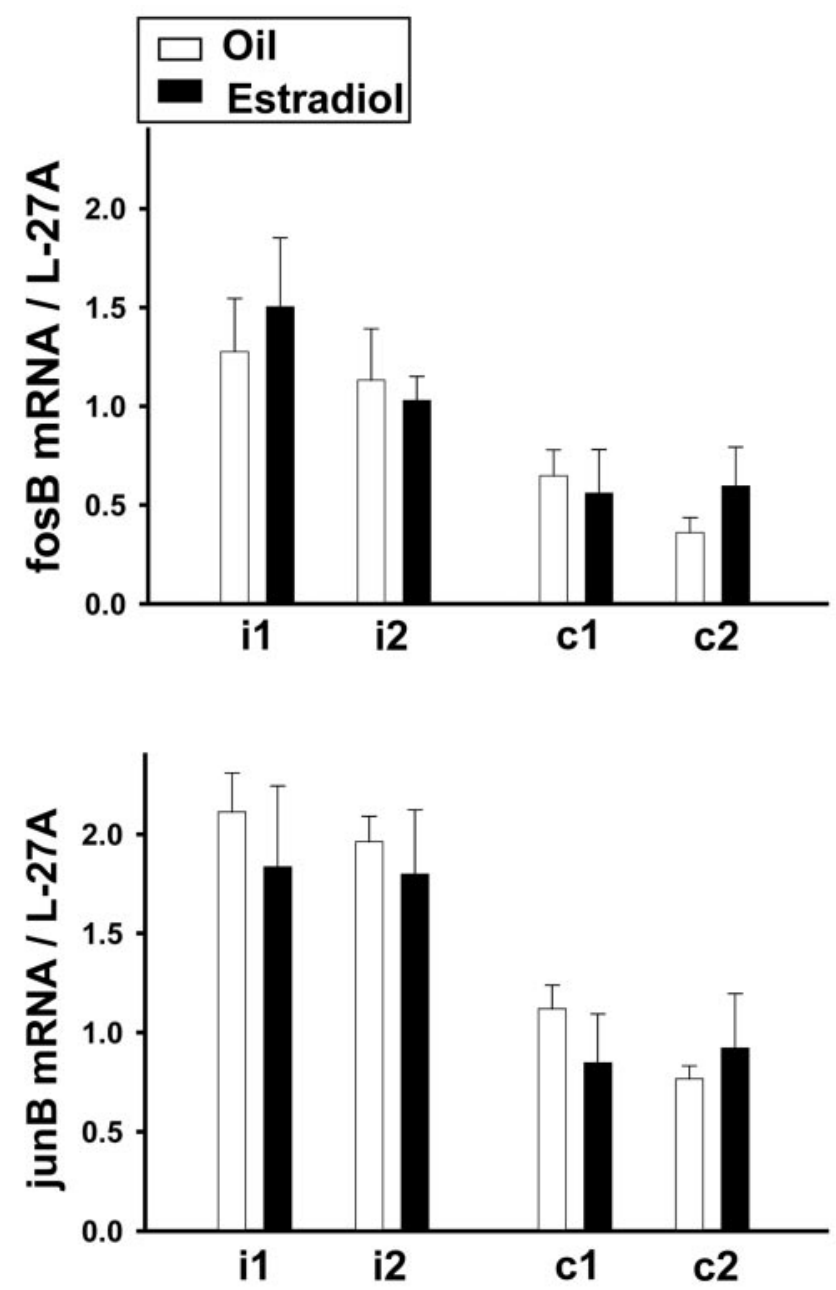

Figure 4. Injury significantly increases the amount of fos $B$ and $j u n B m R N A$ in areas 11 and $i 2$ in comparison with $c 1$ and $c 2$, respectively $(p<0.05)$. Estradiol had no effect on mRNA levels of fos $B$ or jun $B$. Tissue samples were taken from animals in experiment 2 at $24 \mathrm{hr}$ after the initiation of MCAO. Data are represented as mean \pm SEM.

treated animals, $c$-fos mRNA levels exhibited a dramatic rise between 1 and $4 \mathrm{hr}$ after ischemic onset. It should be noted here that $c$-fos expression is absent in the striatum at all time points examined (data not shown). In estradiol-treated animals, the late phase (16-24 hr) injury-mediated increase in c-fos mRNA levels is attenuated in comparison their oil-treated counterparts (Fig. 6) $\left({ }^{*} p<0.05\right)$. 
Oil Estradiol

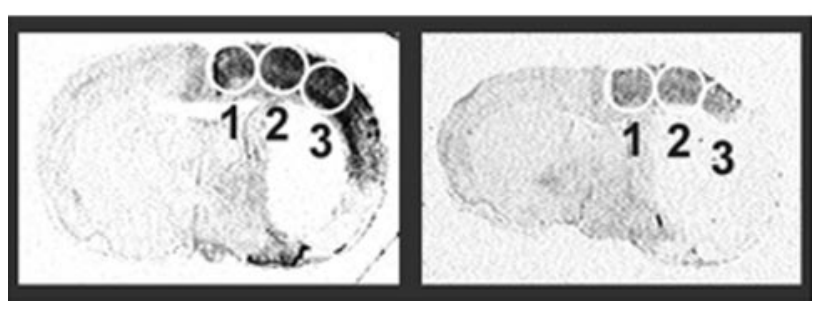

Figure 5. Representative images from autoradiographic films of coronal brain sections from oil- and estradiol-treated animals that underwent $24 \mathrm{hr}$ of permanent MCAO hybridized with radioactive c-fos riboprobe. Areas 1, 2, and 3 demarcate regions from which densitometric measurements were taken using pixel count and area arrays via BIOQUANT software.

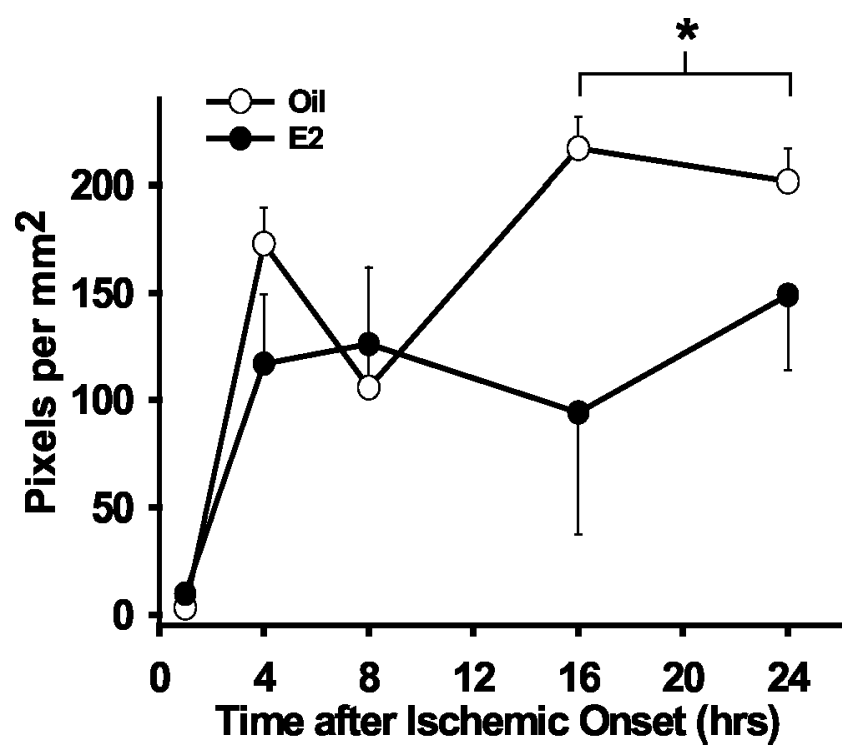

Figure 6. This graph represents quantification of densitometric measurements performed on autoradiographs of coronal sections labeled by riboprobed c-fos mRNA. Sections were taken from animals killed at 1, 4, 8, 16, and $24 \mathrm{hr}$ after initiation of MCA0. Estradiol attenuates injury-mediated c-fos mRNA levels during the late phase of ischemic injury (16-24 hr). c-fos mRNA, measured by in situ hybridization, is induced between 1 and $4 \mathrm{hr}$ after the onset of injury in both oil- and estradiol-treated animals $(p<0.05)$. Estradiol-treated animals show attenuated c-fos mRNA levels at $16-24 \mathrm{hr}$ in comparison with their oil-treated counterparts $\left({ }^{*} p<\right.$ 0.05). Data are represented as mean \pm SEM.

The effects of MCAO and estradiol on $c$-fos mRNA are translated into parallel changes in the c-Fos protein expression pattern

Figure 7 shows representative microscopic fields of c-Fosimmunoreactive brain sections. In oil- and estradiol-treated animals, few c-Fos-positive cells were detected at $1 \mathrm{hr}$ after ischemic onset. In contrast, the number of c-Fos-immunoreactive cells rose dramatically during the early phase of injury in both oil- and estradiol-treated animals. This rise continued in oil-treated animals to an even higher level at $16 \mathrm{hr}$, where it reached a plateau. In estradiol-treated animals, the number of c-Fos-immunoreactive cells reached a plateau at $8 \mathrm{hr}$ and was significantly lower than oil-treated animals during the late phase of injury (16 and $24 \mathrm{hr}$ ) (Fig. 8$)\left({ }^{*} p<0.05\right)$. c-Fos expression by immunohistochemistry is absent from the ischemic striatum (data not shown).

\section{Discussion}

Our studies demonstrate three important findings. First, by $24 \mathrm{hr}$, $\mathrm{MCAO}$ results in an increase in all IEGs that we examined, except
junD. Second, c-Fos mRNA and protein increase within regions of the cerebral cortex in a time- and region-specific manner. Finally, estradiol selectively modulates the injury-induced pattern of c-Fos expression, whereas it shows no significant effect on the other IEGs.

IEG expression is thought to be a crucial part of the programmed cell death pathway since Estus and colleagues (1994) found that induction of cJun and the Fos family were necessary to induce apoptosis in a paradigm of NGF-withdrawal-induced delayed cell death. Administration of antibodies against these IEGs on cultured dorsal root ganglion cells prevented the observed cell death. In this model, increased JunB or JunD expression was not a functionally critical step in the induction of programmed cell death. The same group has also explored IEG involvement in programmed cell death in primary cortical neuronal cultures. Injury of these cultures via amyloid $\beta(\mathrm{A} \beta)$ treatment leads to a robust, time-dependent induction of IEGs. $c$-fos, specifically, was shown to be expressed in a subset of neurons that exhibited condensed chromatin, a hallmark of apoptotic or programmed cell death (Estus et al., 1997). On the basis of these findings, the goal of the present studies was to assess whether estradiol replacement therapy provides protection against MCAOinduced programmed cell death by attenuating the expression of one or more IEGs.

Our results confirm and extend the findings of previous investigators who studied gene expression after focal cerebral ischemic injury and its modulation by neuroprotective factors. Studies have demonstrated increased c-Fos gene expression after focal ischemia in intact male and female animals (Uemura et al., 1991; Kinouchi et al., 1994a; Dietrich et al., 2000). Kinouchi et al. (1994) reported that decreased glutamatergic toxicity, afforded by treatment with MK-801, significantly attenuated MCAOinduced $c$-fos and junB mRNA levels at $4 \mathrm{hr}$ after onset of ischemia. This effect was most pronounced in the cingulate cortex (Kinouchi et al., 1994b). Uemura et al. (1991) examined an injury-mediated increase in c-Fos immunoreactivity after focal ischemia and demonstrated a similar attenuation by treatment with MK-801 (Dietrich et al., 2000). Both Uemura and Kinouchi and their colleagues (Uemura et al., 1991; Kinouchi et al., 1994a) showed a lack of c-Fos expression in the striatum after MCAO, a finding mirrored by the current studies.

The present study combines multiple methods to probe changes in mRNA as well as protein levels across a number of time points. The results clearly reveal that $c$-fos, fosB, $c$-jun, and $j u n B$ are also upregulated in our model of permanent middle cerebral artery occlusion and that c-Fos expression is selectively attenuated by a different neuroprotective factor, estradiol, known to protect against programmed cell death (Jover et al., 2002; Linford and Dorsa, 2002; Monroe et al., 2002; Wilson et al., 2002; Rau et al., 2003). The predominance of the protective effects of estradiol in the cingulate cortex (areas i1, c1), as opposed to the areas of the injured brain that are closer to the infarct (areas i2, c2) (Fig. 3), is reminiscent of the spatial distribution of the protective effects of MK-801 observed by Kinouchi and colleagues (Kinouchi et al., 1994b).

The point on which our results differ from several previous studies is the temporal pattern of c-Fos induction in relation to ischemic injury. Two separate studies using photochemical methods to elicit ischemic injury explored $c$-fos mRNA expression patterns by in situ hybridization. These studies illustrate peaks in $c$-fos expression from 2 to $4 \mathrm{hr}$ with a return to baseline expression by $24 \mathrm{hr}$ after the initiation of ischemic injury (Dietrich et al., 2000; Johansson et al., 2000). Another study demon- 
strates a peak in $c$-fos expression as early as $0.5 \mathrm{hr}$, with return toward baseline by $4 \mathrm{hr}$ after initiation of reperfusion after $2 \mathrm{hr}$ of ischemic injury (Kinoshita et al., 2001). After ischemia induced by a two-vessel occlusion technique, Uemura and colleagues (Uemura et al., 1991) also demonstrated peak $c$-fos expression at 2-4 hr after initiation of ischemia, with a reduction in expression by $8 \mathrm{hr}$ and return to baseline by $2 \mathrm{~d}$. Finally, the study most similar to the work described in this manuscript was published by Kinouchi and colleagues (Kinouchi et al., 1994a). These authors looked at $c$-fos expression after permanent MCAO via an intraluminal suture technique. The authors demonstrated a peak in c-fos expression at $4 \mathrm{hr}$ after artery occlusion, with a return toward baseline expression at 24 hr after artery occlusion (Kinouchi et al., 1994a). These previous studies used varying techniques for induction of ischemia, and all demonstrate an earlier peak in $c$-fos gene expression than our results. Additionally, our results contrast with these previous studies by showing sustained expression of c-Fos mRNA and protein to the endpoint of $24 \mathrm{hr}$. The common difference is that the current study uses ovariectomized female rats, whereas each previous study used intact male rats. This may suggest that sex or gonadal status influences the timing and duration of IEG expression after injury.

Despite the difference in $c$-fos expression patterns, estradiol is able to reduce ischemic infarct size in both ovariectomized female and intact male rats. After transient cerebral ischemia, females sustained $>50 \%$ less infarction than gonadally intact males and ovariectomized females (Alkayed et al., 1998). Our previous studies have shown profound neuroprotective effects after permanent cerebral ischemia in ovariectomized female rats with estradiol pretreatment (Dubal et al., 1998). Intact and castrate males have also been shown to be protected from ischemic injury by estradiol. Toung and colleagues (Toung et al., 1998) demonstrated neuroprotection in intact and castrate male rats by chronic implantation with estradiol pellets in a model of cerebral ischemia with reperfusion injury. The effects of estradiol in this model were independent of relative changes in cortical perfusion as measured by laser Doppler flowmetry (Toung et al., 1998). A separate group, using a model of permanent MCAO by electrocautery, demonstrated neuroprotection by an intravenous bolus of estradiol. Infarct volume was significantly reduced by estradiol given $30 \mathrm{~min}$ before or at the time of MCAO. The estrogen receptor antagonist, ICI-182,780, abolished the neuroprotective actions of estradiol in these studies (Saleh et al., 2001).

Therefore, $17 \beta$-estradiol can protect both the male and female brain from damage by ischemic insult, yet there appears to be a different reaction to ischemic injury in the ovariectomized female and the intact male brain as evidenced by differing patterns of $c$-fos expression. Further study is required to fully explain these intriguing observations.

Cortical c-Fos expression after ischemic injury is known to be linked to an electrical phenomenon known as cortical spreading depression, or alternatively, cortical spreading depolarization (CSD). CSDs contribute to the early phase of expansion of ischemic infarction beyond the ischemic core, as shown by positive correlation between their number and infarct size and also by reductions in their number and amplitude by MK-801 (Gill et al.,
$8 \mathrm{~h}$
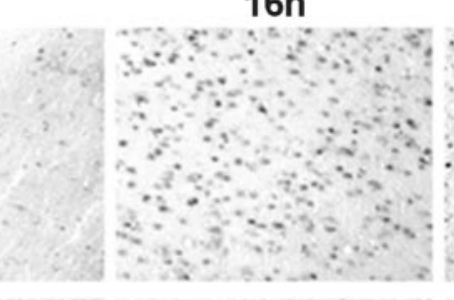

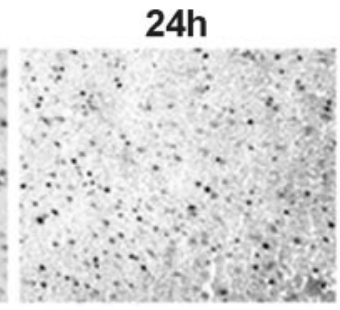

78

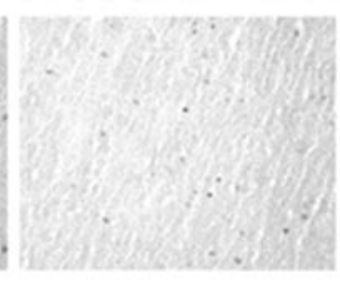

(1)

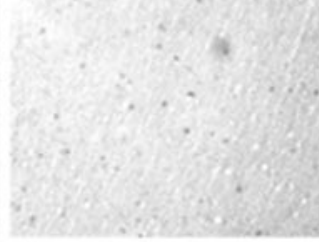

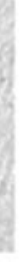
.

Figure 7. Composite of representative $20 \times$ microscope fields from ipsilateral frontal cortex stained immunohistochemically

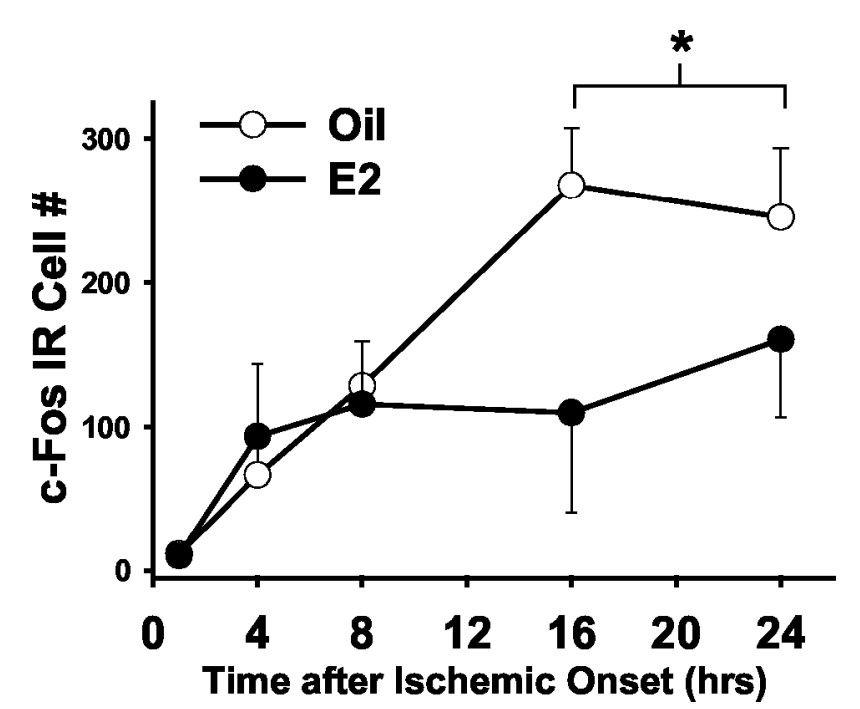

Figure 8. This graph represents quantification of c-Fos immunoreactive (IR) cells counted in ischemic cortex of coronal sections from animals killed at 1, 4, 8, 16, and $24 \mathrm{hr}$ after initiation of MCA0. Estradiol attenuates the number of c-Fos IR cells during the late phase of ischemic injury (16-24 hr). The number of c-Fos IR cells is increased between 1 and $4 \mathrm{hr}$ after the onset of injury in both oil- and estradiol-treated animals $(p<0.05)$. In oil-treated animals, there is a secondary rise between 8 and $16 \mathrm{hr}(p<0.05)$. In estradiol-treated animals, however, there is an attenuation of this secondary rise in number of c-Fos IR cells at $16-24 \mathrm{hr}$ in comparison with their oil-treated counterparts $\left({ }^{*} p<0.05\right)$. Data are represented as mean $\pm \mathrm{SEM}$.

1992; Iijima et al., 1992; Dietrich et al., 2000; for review, see Sharp et al., 2000). A significant body of literature has demonstrated a causal link between postischemic IEG expression and CSD (for review, see Kiessling and Gass, 1994). Given the effects of estradiol on the temporospatial pattern of c-Fos expression in conjunction with its previously observed regionally specific pattern of protection, we speculate that estradiol may be attenuating the occurrence of CSDs in ischemic cortex.

The effects of estradiol on injury-induced c-Fos shed light on the mechanism of estradiol-induced protection, the stage of injury that is protected by estradiol, and the role of IEGs. Specifically, several studies have shown that c-Fos is induced in the cingulate cortex after focal ischemia in intact animals (Herrera and Robertson, 1989; Uemura et al., 1991; Kinouchi et al., 1994a; 
Dietrich et al., 2000). These studies typically show a peak in c-Fos mRNA and protein expression between 1 and $4 \mathrm{hr}$ after the initiation of injury, with a subsequent diminution of expression by 24 hr. Our studies clearly show that in the absence of the gonads, c-Fos expression continues to increase over the $24 \mathrm{hr}$ period after MCAO. Pretreatment with estradiol, the major biologically active ovarian steroid, at levels that mimic the intact state attenuates the further increase that continues during the later time points in ovariectomized rats.

In summary, our results clearly show that the protective effects of estradiol correlate with attenuation of c-Fos gene and protein expression. These findings suggest that the neuroprotective mechanism of estradiol involves a crucial pathway in the early stages of the recruitment of ischemic penumbra into the final infarction. Finally, these studies constitute a significant expansion of our understanding of the protective mechanisms of estradiol in the brain and add to the growing literature exploring potential roles for this powerful hormone.

\section{References}

Alkayed NJ, Harukuni I, Kimes AS, London ED, Traystman RJ, Hurn PD (1998) Gender-linked brain injury in experimental stroke. Stroke 29:159-166.

Alkayed NJ, Murphy SJ, Traystman RJ, Hurn PD (2000) Neuroprotective effects of female gonadal steroids in reproductively senescent female rats. Stroke 31:161-168.

American Heart Association (2001) 2002 Heart and stroke statistical update. Dallas: American Heart Association.

Behl C, Skutella T, Lezoualch F, Post A, Widmann M, Newton CJ, Holsboer F (1997) Neuroprotection against oxidative stress by estrogens: structureactivity relationship. Mol Pharmacol 51:535-541.

Brambilla DJ, McKinlay SM (1989) A prospective study of factors affecting age at menopause. J Clin Epidemiol 42:1031-1039.

Brinton RD (2001) Cellular and molecular mechanisms of estrogen regulation of memory function and neuroprotection against Alzheimer's disease: recent insights and remaining challenges. Learn Mem 8:121-133.

Bromberger JT, Matthews KA, Kuller LH, Wing RR, Meilahn EN, Plantinga P (1997) Prospective study of the determinants of age at menopause. Am J Epidemiol 145:124-133.

Calakos N, Scheller RH (1994) Vesicle-associated membrane protein and synaptophysin are associated on the synaptic vesicle. J Biol Chem 269:24534-24537.

Chomczynski P, Sacchi N (1987) Single-step methods of RNA isolation by acid guanidinium thiocyanate-phenol-chloroform extraction. Anal Biochem 162:156-159.

Chopp M, Li Y (1996) Apoptosis in focal cerebral ischemia. Acta Neurochir 66:21-26.

Curran T, Gordon MB, Rubino KL, Sambucetti LC (1987) Isolation and characterization of the $\mathrm{c}$-fos(rat) cDNA and analysis of post-translational modification in vitro. Oncology 2:79-84.

Dietrich WD, Truettner J, Prado R, Stagliano NE, Zhao W, Busto R, Ginsberg MD, Watson BD (2000) Thromboembolic events lead to cortical spreading depression and expression of c-fos, brain-derived neurotrophic factor, glial fibrillary acidic protein, and heat shock protein $70 \mathrm{mRNA}$ in rats. J Cereb Blood Flow Metab 20:103-111.

Dubal DB, Wise PM (2001) Neuroprotective effects of estradiol in middleaged female rats. Endocrinology 142:43-48.

Dubal DB, Kashon ML, Pettigrew LC, Ren JM, Finklestein SP, Rau SW, Wise PM (1998) Estradiol protects against ischemic injury. J Cereb Blood Flow Metab 18:1253-1258.

Dubal DB, Shughrue PJ, Wilson ME, Merchenthaler I, Wise PM (1999) Estradiol modulates Bcl-2 in cerebral ischemia: a potential role for estrogen receptors. J Neurosci 19:6385-6393.

Estus S, Zaks WJ, Freeman RS, Gruda M, Bravo R, Johnson EM Jr (1994) Altered gene expression in neurons during programmed cell death: identification of $c$-jun as necessary for neuronal apoptosis. J Cell Biol 127:1717-1727.

Estus S, Tucker HM, van Rooyen C, Wright S, Brigham EF, Wogulis M, Rydel $\mathrm{RE}$ (1997) Aggregated amyloid- ${ }_{\beta}$ protein induces cortical neuronal ap- optosis and concomitant "apoptotic" pattern of gene induction. J Neurosci 17:7736-7745.

Ferrer I, Lopez E, Blanco R, Rivera R, Krupinski J, Marti E (2000) Differential c-Fos and caspase expression following kainic acid excitotoxicity. Acta Neuropathol 99:245-256.

Futterman LG, Lemberg L (2000) The Framingham Heart Study: a pivotal legacy of the last millennium. Am J Crit Care 9:147-151.

Garcia Segura LM, Azcoitia I, DonCarlos LL (2001) Neuroprotection by estradiol. Prog Neurobiol 63:29-60.

Gill R, Andine P, Hillered L, Persson L, Hagberg H (1992) The effect of MK-801 on cortical spreading depression in the penumbral zone following focal ischaemia in the rat. J Cereb Blood Flow Metab 12:371-379.

Green PS, Simpkins JW (2000) Neuroprotective effects of estrogens: potential mechanisms of action. Int J Dev Neurosci 18:347-358.

Guegan C, Sola B (2000) Early and sequential recruitment of apoptotic effectors after focal permanent ischemia in mice. Brain Res 856:93-100.

Hall ED, Pazara KE, Linseman KL (1991) Sex differences in postischemic neuronal necrosis in gerbils. J Cereb Blood Flow Metab 11:292-298.

Herrera DG, Robertson HA (1989) Unilateral induction of c-fos protein in cortex following cortical devascularization. Brain Res 503:205-213.

Hoshimaru M, Ray J, Sah DWY, Gage FH (1996) Differentiation of the immortalized adult neuronal progenitor cell line HC2S2 into neurons by regulatable suppression of the v-myc oncogene. Proc Natl Acad Sci USA 93:1518-1523.

Hurn PD, Macrae IM (2000) Estrogen as a neuroprotectant in stroke. J Cereb Blood Flow Metab 20:631-652.

Iijima T, Mies G, Hossmann K-A (1992) Repeated negative DC deflections in rat cortex following middle cerebral artery occlusion are abolished by MK-801: effect on volume of ischemic injury. J Cereb Blood Flow Metab 12:727-733.

Johansson I-M, Wester P, Hakova M, Gu W, Seckl JR, Olsson T (2000) Early and delayed induction of immediate early gene expression in a novel focal cerebral ischemia model in the rat. Eur J Neurosci 12:3615-3625.

Jover T, Tanaka H, Calderone A, Oguro K, Bennett MVL, Etgen AM, Zukin RS (2002) Estrogen protects against global ischemia-induced neuronal death and prevents activation of apoptotic signaling cascades in the hippocampal CA1. J Neurosci 22:2115-2124.

Kawas C, Resnick S, Morrison A, Brookmeyer R, Corrada M, Zonderman A, Bacal C, Lingle D, Metter E (1997) A prospective study of estrogen replacement therapy and the risk of developing Alzheimer's disease: the Baltimore longitudinal study of aging. Neurology 48:1517-1521.

Kiessling M, Gass P (1994) Stimulus-transcription coupling in focal cerebral ischemia. Brain Pathol 4:77-83.

Kim H, Bang OY, Jung MW, Ha SD, Hong HS, Huh K, Kim SU, Mook-Jung I (2001) Neuroprotective effects of estrogen against beta-amyloid toxicity are mediated by estrogen receptors in cultured neuronal cells. Neurosci Lett 302:58-62.

Kinoshita Y, Ueyama T, Senba E, Terada T, Nakai K, Itakura T (2001) Expression of c-fos, heat shock protein 70 , neurotrophins, and cyclooxygenase- 2 mRNA in response to focal cerebral ischemia/reperfusion in rats and their modification by magnesium sulfate. J Neurotrauma 18:435-445.

Kinouchi H, Sharp FR, Chan PH, Koistinaho J, Sagar SM, Yoshimoto T (1994a) Induction of c-fos, c-jun, and hsp70 mRNA in cortex, thalamus, basal ganglia, and hippocampus following middle cerebral artery occlusion. J Cereb Blood Flow Metab 14:808-817.

Kinouchi H, Sharp FR, Chan PH, Mikawa S, Hideyuki K, Arai S, Yoshimoto T (1994b) MK-801 inhibits the induction of immediate early genes in cerebral cortex, thalamus, and hippocampus, but not in substantia nigra following middle cerebral artery occlusion. Neurosci Lett 179:111-114.

Li Y, Powers C, Jiang N, Chopp M (1998) Intact, injured, necrotic and apoptotic cells after focal cerebral ischemia in the rat. J Neurol Sci 156:119-132.

Linford NJ, Dorsa DM (2002) 17beta-estradiol and the phytoestrogen genistein attenuate neuronal apoptosis induced by the endoplasmic reticulum calcium-ATPase inhibitor thapsigargin. Steroids 67:1029-1040.

Luoto R, Kaprio J, Uutela A (1994) Age at natural menopause and sociodemographic status in Finland. Am J Epidemiol 139:64-76.

Marder K, Sano M (2000) Estrogen to treat Alzheimer's disease: too little, too late? So what's a woman to do? Neurology 54:2035-2037.

Mendelowitsch A, Ritz M-F, Ros J, Langemann H, Gratzl O (2001) 17betaestradiol reduces cortical lesion size in the glutamate excitotoxicity model 
by enhancing extracellular lactate: a new neuroprotective pathway. Brain Res 901:230-236.

Miller DB, Ali SF, O'Callaghan JP, Laws SC (1998) The impact of gender and estrogen on striatal dopaminergic neurotoxicity. Ann NY Acad Sci 844:153-165.

Monroe DG, Berger RR, Sanders MM (2002) Tissue-protective effects of estrogen involve regulation of caspase gene expression. Mol Endocrinol 16:1322-1331.

Namura S, Zhu J, Fink K, Endres M, Srinivasan A, Tomaselli KJ, Yuan J, Moskowitz MA (1998) Activation and cleavage of caspase-3 in apoptosis induced by cerebral ischemia. J Neurosci 18:3659-3668.

Paganini-Hill A, Ross RK, Henderson BE (1988) Postmenopausal oestrogen treatment and stroke: a prospective study. Br Med J 297:519-522.

Paxinos G, Watson C (1997) The rat brain in stereotaxic coordinates. New York: Academic.

Rau SW, Dubal DB, Gerhold LM, Wise PM (2003) Estradiol attenuates markers of programmed cell death after focal cerebral ischemia. J Neurosci, in press.

Roof RL, Hall ED (2000) Gender differences in acute CNS trauma and stroke: neuroprotective effects of estrogen and progesterone. J Neurotrauma 17:367-388.

Rusa R, Alkayed NJ, Crain BJ, Traystman RJ, Kimes AS, London ED, Klaus JA, Hurn PD (1999) 17beta-estradiol reduces stroke injury in estrogendeficient female animals. Stroke 30:1665-1670.

Saleh TM, Cribb AE, Connell BJ (2001) Estrogen-induced recovery of autonomic function after middle cerebral artery occlusion in male rats. Am J Physiol Regul Int Comp Physiol 281:R1531-R1539.

Sawada H, Shimohama S (2000) Neuroprotective effects of estradiol in mesencephalic dopaminergic neurons. Neurosci Biobehav Rev 24:143-147.

Sharp FR, Lu A, Tang Y, Millhorn DE (2000) Multiple molecular penumbras after focal cerebral ischemia. J Cereb Blood Flow Metab 20:1011-1032.
Sherwin BB (1999) Can estrogen keep you smart? Evidence from clinical studies. J Psychiatry Neurosci 24:315-321.

Smith MS, Freeman ME, Neill JD (1975) The control of progesterone secretion during the estrous cycle and early pseudopregnancy in the rat: prolactin, gonadotropin and steroid levels associated with rescue of the corpus luteum of pseudopregnancy. Endocrinology 96:219-226.

Toran-Allerand CD, Singh M, Setalo G (1999) Novel mechanisms of estrogen action in the brain: new players in an old story. Front Neuroendocrinol 20:97-121.

Toung TJK, Traystman RJ, Hurn PD (1998) Estrogen-mediated neuroprotection after experimental stroke in male rats. Stroke 29:1666-1670.

Uemura Y, Kowall NW, Moskowitz MA (1991) Focal ischemia in rats causes time-dependent expression of c-fos protein immunoreactivity in widespread regions of ipsilateral cortex. Brain Res 552:99-105.

Wang PN, Liao SQ, Liu RS, Liu CY, Chao HT, Lu SR, Yu HY, Wang SJ, Liu HC (2000) Effects of estrogen on cognition, mood, and cerebral blood flow in AD: a controlled study. Neurology 54:2061-2066.

Wilson ME, Liu Y, Wise PM (2002) Estradiol enhances Akt activation in cortical explant cultures following neuronal injury. Mol Brain Res 102:48-54.

Wise PM, Scarbrough K, Lloyd JM, Weiland NG, Larson GH, Chiu S (1992) Assessment of proopiomelanocortin gene expression in brain. Methods Neurosci 9:197-208.

Wise PM, Dubal DB, Wilson ME, Rau SW, Liu Y (2001) Estrogens: trophic and protective factors in the adult brain. Front Neuroendocrinol 22:33-66.

Writing Group for the Women's Health Initiative Investigators (2002) Risks and benefits of estrogen plus progestin in healthy postmenopausal women. JAMA 288:321-333. 